\title{
A scoping literature review of collaboration between primary care and public health
}

\author{
Ruth Martin-Misener ${ }^{1}$, Ruta Valaitis ${ }^{2}$, Sabrina T. Wong ${ }^{3}$, Marjorie MacDonald ${ }^{4}$, Donna Meagher-Stewart ${ }^{5}$, \\ Janusz Kaczorowski ${ }^{6}$, Linda O-Mara ${ }^{7}$, Rachel Savage ${ }^{8}$, Patricia Austin ${ }^{9}$ and the Strengthening Primary \\ Health Care through Public Health and Primary Care Collaborations Team ${ }^{10}$
}

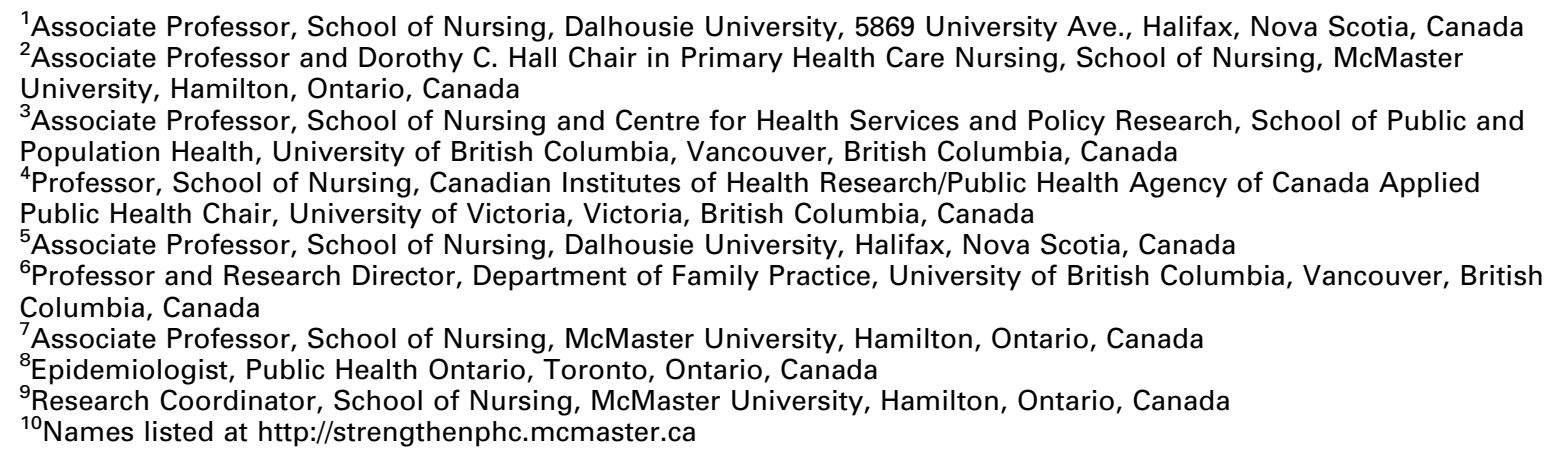

Aim: The purpose of this scoping literature review was to determine what is known about: 1) structures and processes required to build successful collaborations between primary care (PC) and public health $(\mathrm{PH})$; 2) outcomes of such collaborations; and 3) markers of their success. Background: Collaboration between PC and PH is believed to enable more effective individual and population services than what might be achieved by either alone. Methods: The study followed established methods for a scoping literature review and was guided by a framework that identifies systemic, organizational and interactional determinants for collaboration. The review was restricted to articles published between 1988 and 2008. Published quantitative and qualitative primary studies, evaluation research, systematic and other types of reviews, as well as descriptive accounts without an explicit research design, were included if they addressed either the structures or processes to build collaboration or the outcomes or markers of such collaboration, and were published in English. Findings: The combined search strategy yielded 6125 articles of which 114 were included. Systemic-level factors influencing collaboration included: government involvement, policy and fit with local needs; funding and resource factors, power and control issues; and education and training. Lack of a common agenda; knowledge and resource limitations; leadership, management and accountability issues; geographic proximity of partners; and shared protocols, tools and information sharing were influential at the organizational level. Interpersonal factors included having a shared purpose; philosophy and beliefs; clear roles and positive relationships; and effective communication and decision-making strategies. Reported benefits of collaboration included: improved chronic disease management; communicable disease control; and maternal child health. More research is needed to explore the conditions and contexts in which collaboration between PC and $\mathrm{PH}$ makes most sense and potential gains outweigh the associated risks and costs.

Correspondence to: Dr Ruth Martin-Misener NP, PhD, Associate Professor, School of Nursing, Dalhousie University, 5869 University Ave., Halifax, Nova Scotia, B3H 4R2, Canada. Email: ruth.martin-misener@dal.ca

(C) Cambridge University Press 2012 
Key words: collaboration; interorganization; partnership; primary care; primary health care; public health

Received 3 May 2011; accepted 19 September 2011; first published online 21 February 2012

\section{Background}

Worldwide, health systems are revisiting the concept of primary health care (PHC) and trying to understand why the promise of 'health for all' has fallen short of the expectations it once inspired. The multiple, sometimes conflicted, meanings attached to PHC have been confusing, divisive and eroded its potential to improve health. Not only is PHC poorly integrated with the rest of the health system, there are challenges with integration between interventions offered by sectors within the field of PHC (Frenk, 2009). In this article, we focus on how collaboration between two sectors, primary care (PC) and public health $(\mathrm{PH})$, might improve $\mathrm{PHC}$.

We use the definition of PHC articulated in the Alma Ata Declaration; PHC is 'essential health care based on practical, scientifically sound and socially acceptable methods and technology made universally accessible to individuals and families in the community through their full participation and at a cost that the community and country can afford to maintain at every stage of their development in the spirit of self reliance and self-determination' (World Health Organization [WHO], 1978: 1). We make a distinction between PHC and PC, not to resurrect old debates, but to make clear, as others have done (Muldoon et al., 2006; Russell et al., 2007) that PHC is a broad term conceptualizing an approach to health policy and services for individuals and populations that includes $\mathrm{PC}, \mathrm{PH}$ and other services and sectors. As the first point of entry to a healthcare system, PC provides person-focused, integrated, coordinated care over time for all but the most uncommon conditions (Starfield, 1998). We define PH to be 'an organized activity of society to promote, protect and improve, and when necessary, restore the health of individuals, specified groups, or the entire population. It is a combination of sciences, skills, and values that function through collective societal activities and involve programs, services, and institutions aimed at protecting and improving the health of all people' (Public Health Agency of Canada, 2007: 13).
Collaboration between $\mathrm{PC}$ and $\mathrm{PH}$ is believed to enable the delivery of more effective clinical services, community screening and public education campaigns than what might be achieved by either of these sectors alone (Lasker, 2002; Weiss et al., 2002). According to Lasker, when the practicebased services for individuals offered by PC are combined with the population-based strategies offered by $\mathrm{PH}$, health services can become more accessible and tailored to community needs, and better equipped to manage the origins of health problems. Lasker and The Committee on Medicine and Public Health's (1997) framework for PC and PH collaboration includes: a shared goal; the full range of health and disease determinants; the people and organizations that can make an impact on these determinants; the diverse resources and skills of partners; and the types of interventions that can be mounted. The focus of the interventions in a PC and $\mathrm{PH}$ collaboration can be to increase service coordination, increase accessibility for the uninsured, enhance the quality and costeffectiveness of care, identify and address community problems, strengthen health promotion and health protection and shape the health system through policy, training and research (Lasker and The Committee on Medicine and Public Health, 1997). We used the Public Health Agency of Canada (1997: 9) definition of collaboration, 'a recognized relationship among different sectors or groups, which have been formed to take action on an issue in a way that is more effective or sustainable than might be achieved by the public health sector acting alone'.

Shifting patient population and health service trends, together with an increased focus on population health and health determinants, are some of the drivers propelling the exploration of collaboration between PC and PH. In the United States, the fiscal pressures associated with providing care for a growing uninsured patient population have influenced the leverage attributed to collaboration (Lasker and The Committee on Medicine and Public Health, 1997). In the United Kingdom, efforts to integrate PC and PH began in the 1990s

Primary Health Care Research \& Development 2012; 13: 327-346 
with the establishment of Primary Care Groups, and later Primary Care Trusts, which have a requirement to engage in strategic planning, needs assessment and service evaluation (Gillam et al., 1998; The Change Foundation, 2009). In Canada, after decades of little progress (Hutchison et al., 2001), PHC renewal efforts have ramped up with an unprecedented momentum (Hutchison, 2008) with growing recognition that stronger collaboration between PC and PH is needed (Dault et al., 2004; Ontario Ministry of Health and Long Term Care, 2006; Rachlis, 2006; The Change Foundation, 2009). Concurrently, in the wake of disasters such as SARS, the tainted blood scandal (transfusions of blood contaminated with hepatitis $\mathrm{C}$ ) and water contamination, calls to renew $\mathrm{PH}$ have led to improvements in human resource planning and management (Canadian Institutes of Health Research [CIHR], 2003; Naylor et al., 2003; Joint Task Group on Public Health Human Resources, 2005).

In this article, we report on a scoping review of the literature that examines collaboration between $\mathrm{PC}$ and $\mathrm{PH}$. The purpose of the review was to determine what was known from published quantitative and qualitative studies, evaluation research, systematic and other types of literature reviews as well as descriptive accounts without an explicit research design about structures and processes required to build successful collaborations between $\mathrm{PH}$ and PC, outcomes of these collaborations and markers of their success.

\section{Methods}

The study followed established scoping literature review methods (Arksey and O'Malley, 2005; Anderson et al., 2008; Rumrill et al., 2010) and was guided by a framework that identifies three determinants for collaboration (San Martin-Rodriguez et al., 2005). Systemic determinants reside in the environment outside of the organization where the collaboration takes place. Organizational determinants are conditions within the organization, and interactional determinants refer to the interpersonal interactions between team members. This framework guided data extraction and coding of articles included in the review. A detailed description of our methods is published in another paper in this issue (Valaitis et al., in press); therefore, here, we report only key points.
Nine databases (MEDLINE, CINAHL, Cochrane, DARE, Dissertations International, EPOC, EMBASE, PsycINFO and Sociological Abstracts) were searched from 1988 (10 years following Alma Ata) to May 2008 using Mesh Headings and free text key words that were applicable to $\mathrm{PH}, \mathrm{PC}$ and collaboration - in combinations using the Boolean operators 'AND' and 'OR' (Table 1). Two librarians developed a search strategy independently and, after comparing results, agreed on a single strategy. To update our review, the same databases were searched for systematic and other types of review articles in July 2011 yielding four relevant articles that we consider in our discussion of the review results. Additional strategies included a search of relevant websites, hand searching of relevant journals and the references in two review articles (Ciliska et al., 2005; Stevenson Rowan et al., 2007) and contact with content experts (Valaitis et al., in press). To enable some comparability of heathcare systems, the review was restricted to articles about collaboration between $\mathrm{PC}$ and $\mathrm{PH}$ in Canada, United States, Western Europe, Australia and New Zealand. We included primary studies of all types, theses, literature reviews of all types, including systematic reviews, and descriptive accounts of collaboration without an explicit research design if they addressed either structures or processes to build collaboration between PC and PH, outcomes of collaboration or markers of success, and were published in English.

The title and abstract of each article was independently evaluated by two researchers, as were articles assessed as relevant. Disagreements were resolved by consensus by the co-principal investigators (R.M.M. and R.V.). Data were extracted using a specifically designed and pilot-tested form derived from detailed research questions. Consistent with a narrative approach (Arksey and O'Malley, 2005), extractors recorded details of structures and processes of programs or interventions to contextualize results. Data extracted included the purpose of the collaboration, participants in the collaboration, research methods used, if any, the site or context of where the collaboration occurred, theoretical framework applied, if any, what precipitated and or motivated the collaboration, activities of professionals and disciplines, barriers and facilitators to and results or outcomes of collaboration and indicators of a successful collaboration. A compendium 
Table 1 Keywords for electronic database search

\begin{tabular}{lll}
\hline Primary care & Population health & Collaboration \\
Primary health care & Community health & Partnership \\
Primary healthcare & Public health & Alliance \\
Comprehensive primary health care & Nurse practitioner & Teamwork \\
Primary medical care & Advanced practice nurse/ nursing & Affiliation \\
Community-oriented primary care & Advanced nursing practice & Integration \\
Medicine & Clinical nurse specialist & Cooperation \\
Family medicine & Public health nurse/nursing & Communication \\
Family physician & Community health nurse/ nursing & Coalition \\
General practitioner & & Connection \\
& & Linkage \\
Evidence & & Network(s) \\
Effectiveness & Best practice & Evaluation \\
\hline
\end{tabular}

containing the complete extraction forms, most of which are one page in length, for all 114 articles can be obtained by contacting the corresponding author. Each extraction form was imported separately as a 'source' into NVivo 8 (QSR International Pty Ltd, 2008). Guided by the research questions and the San Martin-Rodriguez et al. (2005) determinants of collaboration framework described previously, the first two authors developed the coding structure for analysis in consultation with the research team. Extractions were analyzed using content analysis with first-level coding followed by categorization into larger themes.

\section{Results}

The combined search strategy yielded 6125 articles. Of these, 114 articles met the inclusion criteria. In the interests of brevity, Table 2 lists the first author of these articles alphabetically. The majority of articles originated from the United Kingdom (38\%) and the United States (34\%; Valaitis et al., in press). Most articles described local collaborations in urban and rural settings often involving physicians and nurses and were reported at organizational and interactional levels. The results presented here are a high-level overview. Details about the aims of the interventions and collaborations and the activities of professionals and organizations involved in collaborations are identified in the compendium of extraction forms for each article available from the first author.

\section{Types of collaboration}

We used Lasker and The Committee on Medicine and Public Health's (1997) synergies of medicine and $\mathrm{PH}$ collaboration to guide categorization of the types of collaboration found in our review. These include collaborations aimed at: improving health care by coordinating services for individuals; improving access to care by establishing frameworks to provide care for uninsured; improving the quality and cost-effectiveness of care by applying a population perspective to medical practice; using clinical practice to identify and address community health problems; strengthening health promotion and health protection by mobilizing community campaigns; and shaping the future direction of the health system by collaborating around policy, training and research (Lasker and The Committee on Medicine and Public Health, 1997: 51). The most commonly reported types of collaboration were those aimed at improving the quality and cost-effectiveness of care by applying a population perspective to PC $(22 \%)$, and those that used clinical practice to identify and address community problems $(17 \%)$. Other types, representing collaborations that focused on integration and/or quality improvement, primarily included numerous papers from the United Kingdom that reported on collaboration in efforts to achieve a model of an integrated health system (Wood et al., 1994; Gerrish, 1999; Headland et al., 2000; Banks-Smith et al., 2001; Bindman et al., 2001; Hurst et al., 2002; Edmonstone et al., 2003; Roff, 2003; Heller and Goldwater, 2004; Meyrick, 2004; Hopayian et al., 2005; Marks and Hunter, 2005; Shaw et al., 2006; Brown et al., 2007). Collaborations aiming to

Primary Health Care Research \& Development 2012; 13: 327-346 
Table 2 Articles included in scoping review listed by first author

\begin{tabular}{|c|c|c|}
\hline $\begin{array}{l}\text { Alexy and Elnitsky (1996) } \\
\text { Andrews (2002) } \\
\text { Arora et al. (2000) } \\
\text { Asaid and Riley (2007) } \\
\text { Ayres et al. (1996) } \\
\text { Banks-Smith et al. (2001) } \\
\text { Baptiste and Drennan (1999) }\end{array}$ & $\begin{array}{l}\text { Harris et al. (2003) } \\
\text { Harrison et al. (2006) } \\
\text { Harrison and Keen (2002) } \\
\text { Headland et al. (2000) } \\
\text { Heller and Goldwater (2004) } \\
\text { Heller et al. (2003) } \\
\text { Hogg et al. (2006a) }\end{array}$ & $\begin{array}{l}\text { O'Neil and Clarkson (2002) } \\
\text { Olney and Yoon (2007) } \\
\text { Oros et al. (2001) } \\
\text { Pierce et al. (2007) } \\
\text { Porter et al. (2007) } \\
\text { Poulton (2000) } \\
\text { Public Health Research Education and } \\
\quad \text { Development (PHRED) (2006) }\end{array}$ \\
\hline Bennett et al. (1994) & Hogg et al. (2006b) & Record et al. (2000) \\
\hline Billingham and Perkins (1997) & Hogg and Hanley (2008) & Renfrew et al. (2001) \\
\hline Bindman et al. (2001) & Hopayian et al. (2005) & Riley et al. (2003) \\
\hline Bourdages et al. (2003) & Hripcsak et al. (1999) & Roff (2003) \\
\hline Brauer et al. (2006) & Hurst et al. (2002) & Rogers et al. (1999) \\
\hline Brown and van Zwanenberg (1989) & Huston et al. (2006) & Rothman et al. (2005) \\
\hline Brown (2006) & Iliffe et al. (2002) & Russell et al. (2003) \\
\hline Brown et al. (2007) & Iliffe and Lenihan (2003) & Sanders et al. (2008) \\
\hline Butler-Jones (2004) & Jackson and Marley (2007) & Scott (1999) \\
\hline Carlisle et al. (2004) & Jenkins and Sullivan-Marx (1994) & Shandro (2003) \\
\hline Chambers et al. (2005) & Jewell and Griffiths (2001) & Shaw et al. (2006) \\
\hline CIHR (2003) & Jordan et al. (1998) & Shirin and Absher (2006) \\
\hline Ciliska et al. (1992) & Kaufman et al. (2006) & Stephenson Rowan (2007) \\
\hline Ciliska et al. (2005) & Kearney et al. (2005) & Taylor et al. (2007) \\
\hline Cook et al. (2001) & Kilduff et al. (1998) & Thackway et al. (2000) \\
\hline Cook $(2000)$ & Koponen and Kalkas (1997) & The Network (2008) \\
\hline Cornell (1999) & Lambrew et al. (1993) & Thomas et al. (1995) \\
\hline Crump et al. (1999) & Larson et al. (2006) & Voelker (1994) \\
\hline Danila et al. (1997) & Lasker and The Committee on & Wedel et al. (2007) \\
\hline de Guzman (2007) & Medicine and Public Health (1997) & Welton et al. (1997) \\
\hline Desai et al. (2003) & Lea et al. (2005) & Wiles and Robison (1994) \\
\hline Dion (2004) & Leeds et al. (2000) & Williams et al. (1999) \\
\hline Edmonstone et al. (2003) & Lemelin et al. (2001) & Wilson et al. (2000) \\
\hline Elster et al. (2002) & Lundeen et al. (1997) & Wood et al. (1994) \\
\hline Ewles (1999) & Machala and Miner (1994) & Xyrichis and Lowton (2008) \\
\hline Fatchett (1990) & Mack et al. (2007) & \\
\hline Ferguson et al. (1992) & Malcolm and Barnett (1995) & \\
\hline Ferrari and Rideout (2005) & Margolis et al. (2001) & \\
\hline Fraser (2005) & Marks and Hunter (2005) & \\
\hline Gerrish (1999) & Mayo et al. (1996) & \\
\hline Gillam et al. (1998) & McDonald et al. (1997) & \\
\hline Gillam and Schamroth (2002) & McElmurry et al. (2009) & \\
\hline Harris et al. (2007) & Meyrick (2004) & \\
\hline Harper et al. (2000) & Michener et al. (2005) & \\
\hline & Morgan and Kelly (2004) & \\
\hline
\end{tabular}

improve access to care by establishing frameworks to provide care for the uninsured were only reported in articles originating from the United States (Machala and Miner, 1994; Lasker and The Committee on Medicine and Public Health, 1997; Wilson et al., 2000; Oros et al., 2001; McElmurry et al., 2009). Another commonly reported type of collaboration was academic partnerships initiated to concurrently improve service delivery and broaden students' educational experiences (Bennett et al., 1994; Lundeen et al., 1997; Williams et al., 1999; Wilson et al., 2000; Oros et al., 2001;
Desai et al., 2003; Morgan and Kelly, 2004; Ferrari and Rideout, 2005; Michener et al., 2005; Rothman et al., 2005; Harrison et al., 2006).

\section{Activities carried out in collaborations}

Collaborations between PC and $\mathrm{PH}$ served a variety of client populations, and, as Figure 1 shows, involved a full range of activities. Community activities included community engagement and participation (Bennett et al., 1994; Alexy and Elnitsky, 1996; Billingham and Perkins, 1997; 


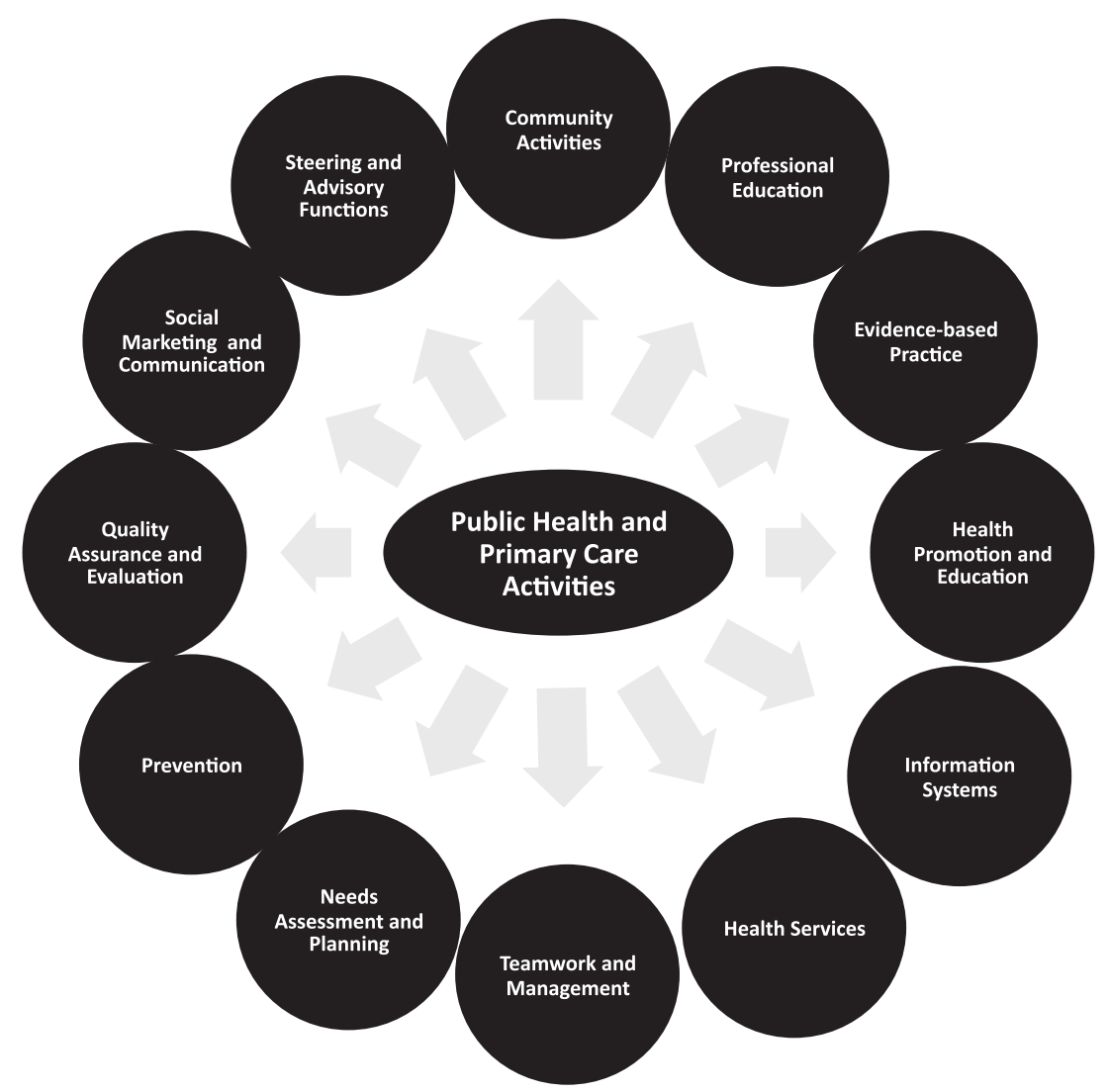

Figure 1 Activities in Primary Care and Public Health Collaborations

Lundeen et al., 1997; McDonald et al., 1997; Ewles, 1999; Harper et al., 2000; Margolis et al., 2001; Oros et al., 2001; Heller et al., 2003; Carlisle et al., 2004; Andrews, 2002; Fraser, 2005; Michener et al., 2005; Rothman et al., 2005; Asaid and Riley, 2007), community development (Billingham and Perkins, 1997; Heller and Goldwater, 2004; Brown et al., 2007) and multi-sectoral involvement (Billingham and Perkins, 1997; Arora et al., 2000; Wilson et al., 2000). Various types of jointly offered health promotion (Fatchett, 1990; Wiles and Robison, 1994; Wood et al., 1994; Lasker and The Committee on Medicine and Public Health, 1997; Cook, 2000; Bindman et al., 2001; Oros et al., 2001; Heller et al., 2003; Riley et al., 2003; Dion, 2004; Kearney et al., 2005; Rothman et al., 2005; Brown, 2006; Sanders et al., 2008), health education (Lambrew et al., 1993; Bennett et al., 1994; Alexy and Elnitsky, 1996; Harper et al., 2000; Record et al., 2000; Thackway et al., 2000; Bourdages et al., 2003; Harris et al., 2003; Heller and Goldwater, 2004; Ferrari and Rideout, 2005; Kearney et al., 2005; Mack et al., 2007; McElmurry et al., 2009; Sanders et al., 2008) and illness/injury prevention initiatives (Lasker and The Committee on Medicine and Public Health, 1997; Lundeen et al., 1997; Crump et al., 1999; Rogers et al., 1999; Lemelin et al., 2001; O'Neil and Clarkson, 2002; Heller et al., 2003; Heller and Goldwater, 2004; Meyrick, 2004; Chambers et al., 2005; Kearney et al., 2005; Brown, 2006; Harrison et al., 2006; PHRED, 2006; Stevenson Rowan et al., 2007) were reported. The most commonly offered health services were general PC services (Alexy and Elnitsky, 1996; Lundeen et al., 1997; Poulton, 2000; Record et al., 2000; Andrews, 2002; Heller and Goldwater, 2004; Ferrari and Rideout, 2005; Brown, 2006; Kaufman et al., 2006; Shirin and Absher, 2006; de Guzman, 2007; Jackson and Marley, 
2007; Taylor et al., 2007), chronic disease management including screening (Alexy and Elnitsky, 1996; Rogers et al., 1999; Record et al., 2000; CIHR, 2003; Chambers et al., 2005; Ferrari and Rideout, 2005; Brown, 2006; PHRED, 2006; Mack et al., 2007; Wedel et al., 2007) and immunization and communicable disease control (Lambrew et al., 1993; Bennett et al., 1994; Wood et al., 1994; Alexy and Elnitsky, 1996; Danila et al., 1997; Crump et al., 1999; Harper et al., 2000; Russell et al., 2003; Heller and Goldwater, 2004; Ferrari and Rideout, 2005; Harris et al., 2007). Several collaborations involved information systems activities such as developing or managing information systems (Voelker, 1994; Hripcsak et al., 1999; Renfrew et al., 2001; Shandro, 2003; Heller and Goldwater, 2004; Meyrick, 2004; Mack et al., 2007) and sharing information (Shandro, 2003; Harris et al., 2007). Development or implementation of best practice guidelines using a variety of strategies was reported (Lambrew et al., 1993; Wood et al., 1994; McDonald et al., 1997; Crump et al., 1999; Cook, 2000; Wilson et al., 2000; Shandro, 2003; Michener et al., 2005; Huston et al., 2006; Larson et al., 2006) as well as a leadership role for $\mathrm{PH}$ in promoting such guidelines (Lasker and The Committee on Medicine and Public Health, 1997; Welton et al., 1997; Cornell, 1999; Hurst et al., 2002; Hopayian et al., 2005). Activities carried out by $\mathrm{PH}$ in collaborations with $\mathrm{PC}$ included conducting needs assessments (Billingham and Perkins, 1997; Lasker and The Committee on Medicine and Public Health, 1997; Kilduff et al., 1998; Poulton, 2000; Wilson et al., 2000; Bindman et al., 2001; Gillam and Schamroth, 2002; Heller et al., 2003; Roff, 2003; Dion, 2004; Meyrick, 2004; Brauer et al., 2006; Brown, 2006; de Guzman, 2007; Stevenson Rowan et al., 2007; Taylor et al., 2007; Wedel et al., 2007), planning programs (Cornell, 1999; Cook, 2000; Oros et al., 2001; Desai et al., 2003; Wedel et al., 2007) and carrying out quality assurance and evaluation (Bindman et al., 2001; Hurst et al., 2002; Bourdages et al., 2003; Hogg et al., 2006a; Brown et al., 2007; de Guzman, 2007; Harris et al., 2007). Teamwork and management activities tended to focus on supporting teams and measures to address client and service concerns or practice governance (Ciliska et al., 1992; Wood et al., 1994; Malcolm and Barnett, 1995; Gillam et al., 1998; Cook, 2000; Headland et al., 2000; Banks-Smith et al., 2001; Bindman et al., 2001; Hurst et al., 2002; Bourdages et al., 2003; Edmonstone et al., 2003; Riley et al.,
2003; Asaid and Riley, 2007). Professional education initiatives included academic programming (Mayo et al., 1996; Harris et al., 2003; Heller and Goldwater, 2004; Morgan and Kelly, 2004; Lea et al., 2005; Kaufman et al., 2006) and informal training initiatives (Wood et al., 1994; Thomas et al., 1995; Welton et al., 1997; Gillam et al., 1998; Cornell, 1999; Scott, 1999; Bindman et al., 2001; Gillam and Schamroth, 2002; Harris et al., 2003; Huston et al., 2006; Harris et al., 2007; Hogg and Hanley, 2008; McElmurry et al., 2009). Advisory board and committee participation (Alexy and Elnitsky, 1996; Kilduff et al., 1998; Margolis et al., 2001; Iliffe et al., 2002; Desai et al., 2003; Dion, 2004; Rothman et al., 2005) and social marketing and communication campaigns about health issues (Danila et al., 1997; Lasker and The Committee on Medicine and Public Health, 1997; Hripcsak et al., 1999; O'Neil and Clarkson, 2002; Kearney et al., 2005; Sanders et al., 2008) were also reported.

The characteristics of successful collaboration between PC and $\mathrm{PH}$ as well as structural and process factors influencing collaboration are briefly discussed in the following section and summarized in Figure 2. Results are presented according to the three determinants for collaboration (systemic, organizational and interactional) as proposed in the framework by San Martin-Rodriguez et al. (2005).

\section{Systemic factors influencing collaboration}

\section{Government involvement, policy and fit with local needs}

Health reform and government mandates for development of teams and partnerships were important systemic factors enabling collaboration reported in UK articles (Wiles and Robison, 1994; Wood et al., 1994; Gillam et al., 1998; Arora et al., 2000; Poulton, 2000; Banks-Smith et al., 2001; Cook et al., 2001; Jewell and Griffiths, 2001; Hurst et al., 2002; Iliffe and Lenihan, 2003; Riley et al., 2003; Meyrick, 2004; Shaw et al., 2006; Brown et al., 2007), and to a lesser extent, in articles from Canada (Shandro, 2003; Butler-Jones, 2004; Brauer et al., 2006; Sanders et al., 2008) and the United States (Jenkins and Sullivan-Marx, 1994; Lasker and The Committee on Medicine and Public Health, 1997). Collaboration between PC and PH occurred more commonly where initiatives had common goals such as reducing health disparities 


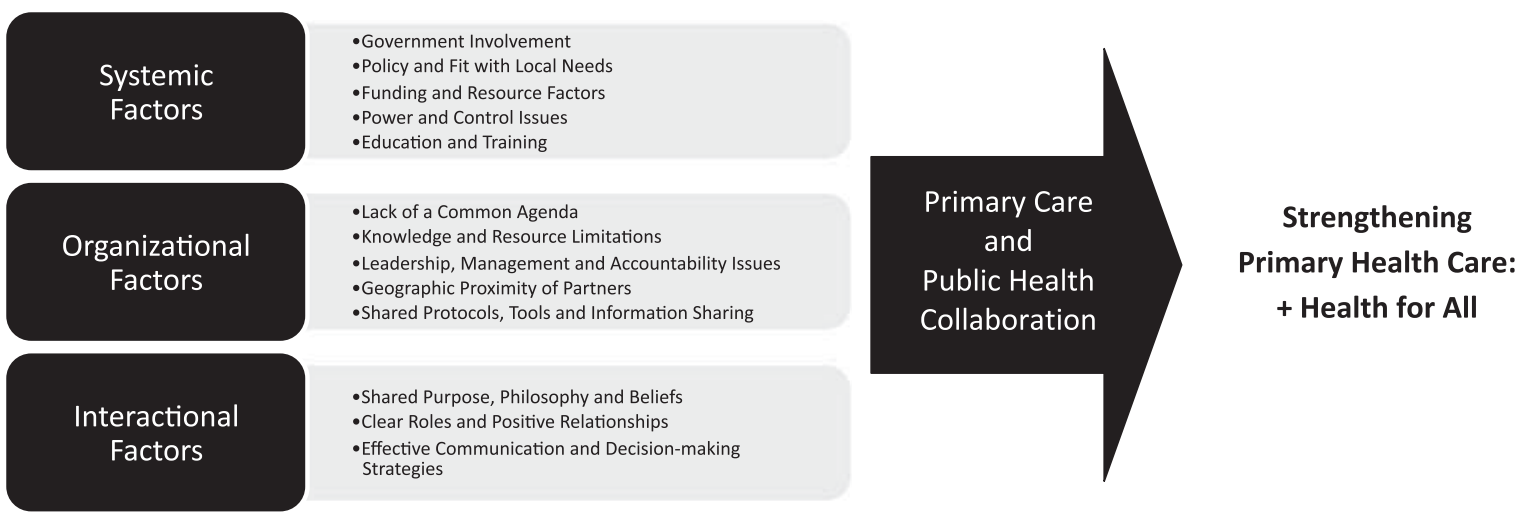

Figure 2 Factors Influencing Collaboration between Primary Care and Public Health

and meeting the healthcare needs of disadvantaged populations (Lasker and The Committee on Medicine and Public Health, 1997; Wilson et al., 2000; Elster et al., 2002; Harrison et al., 2006; PHRED, 2006; Wedel et al., 2007; McElmurry et al., 2009), improving quality of care (Ferguson et al., 1992; Alexy and Elnitsky, 1996; Lundeen et al., 1997; Harris et al., 2003; Heller and Goldwater, 2004), containing costs (Lambrew et al., 1993; Voelker, 1994; Lasker and The Committee on Medicine and Public Health, 1997; Welton et al., 1997; Hripcsak et al., 1999; Williams et al., 1999), enhancing evidence-informed practice (Cornell, 1999; Jordan et al., 1998; Gillam and Schamroth, 2002; Hopayian et al., 2005; Larson et al., 2006) and improving emergency planning and response (Hogg et al., 2006b; Harris et al., 2007; Mack et al., 2007; Pierce et al., 2007; Taylor et al., 2007). Collaboration was, however, also negatively impacted by the rapid and constant change created by healthcare reform (Welton et al., 1997; Hopayian et al., 2005). Newly created structures and governance processes could lead to uncertainty about the processes of PC and PH collaborations (Ciliska et al., 2005). Healthcare reform became a barrier to collaboration when national priorities took precedence over community-level priorities (Ewles, 1999).

Government involvement, including the 'fit' of collaboration with a government's agenda and endorsement of the value of collaboration by government officials (Lambrew et al., 1993; Shandro, 2003) were important facilitators (Harrison and Keen, 2002; Riley et al., 2003; Sanders et al., 2008). The importance of collaboration between levels of government, for example, in an emergency (Taylor et al., 2007), and coordination and priority setting to enhance collaboration were stressed (Ciliska et al., 2005). Relevant policy development was especially emphasized, one example being the reorganization of fiscal and structural resources to create Primary Care Groups in the United Kingdom (Bindman et al., 2001).

\section{Funding and resource factors}

Collaborations were successful, for the most part, if they were adequately funded (Lambrew et al., 1993; Poulton, 2000; Kaufman et al., 2006; Olney and Yoon, 2007; Wedel et al., 2007). Interestingly, not all successful collaborations required additional investments (Lasker and The Committee on Medicine and Public Health, 1997); some pooled and shared resources (CIHR, 2003) and capitalized on volunteer and in-kind contributions (Lundeen et al., 1997; PHRED, 2006; Shaw et al., 2006).

Collaboration between $\mathrm{PC}$ and $\mathrm{PH}$ was impeded where a lack of resources for evaluation, health promotion activities and information infrastructure for reporting, sharing and comparing data, human resources and time occurred (Ciliska et al., 1992; Billingham and Perkins, 1997; McDonald et al., 1997; Cornell, 1999; Gerrish, 1999; Rogers et al., 1999; Bindman et al., 2001; Lemelin et al., 2001; Edmonstone et al., 2003; Iliffe and Lenihan, 2003; Hopayian et al., 2005; Kearney et al., 2005; de Guzman, 2007; Stevenson Rowan et al., 2007; Xyrichis and Lowton, 2008). Fee-for-service remuneration of physicians impeded collaboration 
while alternatives such as capitation, salary or blended funding models enabled them to delegate tasks, allowing more opportunity to provide community-based care (Wedel et al., 2007; The Network Towards Unity for Health, 2008). The intermittent or short-lived nature of some pilot or demonstration projects was another impediment (Arora et al., 2000; Hogg and Hanley, 2008).

At a broader level, other challenges related to distribution of funds across health sectors and dominance of an illness rather than a health paradigm (Lemelin et al., 2001). Financial performance incentives were criticised for preferentially encouraging some health promotion activities in $\mathrm{PC}$ at the expense of those not incentivized (Hogg and Hanley, 2008). The small size of PH departments and their capacity to respond to the imperative for more collaboration with $\mathrm{PC}$ was a concern (Cornell, 1999; CIHR, 2003), and there was apprehension that population expertise and programs could be diluted if absorbed into PC (CIHR, 2003).

\section{Power and control issues}

Many successful collaborations between PC and $\mathrm{PH}$ were driven by values and beliefs, most commonly a belief in the value of collaboration between sectors (Fatchett, 1990; Ayres et al., 1996; Hripcsak et al., 1999; Williams et al., 1999; Elster et al., 2002; Butler-Jones, 2004; Dion, 2004; Chambers et al., 2005; Fraser, 2005; Shaw et al., 2006; Harris et al., 2007; Stevenson Rowan et al., 2007), the value of prevention, health promotion and population heath (Fatchett, 1990; Jenkins and Sullivan-Marx, 1994; Lasker and The Committee on Medicine and Public Health, 1997; Jordan et al., 1998; Elster et al., 2002; Desai et al., 2003; Brauer et al., 2006; Olney and Yoon, 2007) and the importance of teamwork for enabling effective coordinated care (Cook et al., 2001; Xyrichis and Lowton, 2008). Less-successful collaborations were characterized by separate and siloed bureaucracies of PC and PH (The Network Towards Unity for Health, 2008). Territorial ownership conflicts about programs and mandates were common concerns at the systems and organizational levels (Jenkins and Sullivan-Marx, 1994; Wiles and Robison, 1994; Malcolm and Barnett, 1995; Lasker and The Committee on Medicine and Public Health, 1997; Bindman et al., 2001; Hopayian et al., 2005; Mack et al., 2007; Wedel et al., 2007).

\section{Education and training}

Interdisciplinary education (Ciliska et al., 2005) emphasizing system-wide collaborative work practices (Welton et al., 1997; The Network Towards Unity for Health, 2008) and training in PH (Carlisle et al., 2004) are needed. There were calls for education programs to bridge knowledge gaps and prepare graduates for practice in integrated systems (Carlisle et al., 2004; Brown, 2006) and training to expand managerial abilities in facilitating large diverse teams (Banks-Smith et al., 2001; Harrison and Keen, 2002; Iliffe and Lenihan, 2003; Hogg and Hanley, 2008). Furthermore, evaluation skill development is needed in applying $\mathrm{PH}$ concepts in PC (Jordan et al., 1998; Gillam and Schamroth, 2002; Iliffe and Lenihan, 2003).

\section{Organizational factors}

\section{Lack of a common agenda}

Successful collaboration was most likely to occur with organizational support and resources. Lack of organizational support, which restricted collaboration, took many forms including lack of a common agenda (Kilduff et al., 1998; Dion, 2004; Brauer et al., 2006; Brown, 2006; Hogg and Hanley, 2008) or vision (Arora et al., 2000; Shandro, 2003; Shaw et al., 2006; Wedel et al., 2007), as well as dominating (Harrison and Keen, 2002) and competing agendas (Welton et al., 1997; Heller et al., 2003; Ciliska et al., 2005; Hopayian et al., 2005; Hogg and Hanley, 2008). Differences in organizational culture, such as PC's focus on individuals and short-term results, and PH's focus on populations and long-term view of health, limited their collaboration (Welton et al., 1997; Arora et al., 2000; Edmonstone et al., 2003). Added to this, PC was reported to devalue aspects of $\mathrm{PH}$ activities such as prevention, population needs assessments, and community development (Ayres et al., 1996; Billingham and Perkins, 1997; Jordan et al., 1998; Kilduff et al., 1998; Hurst et al., 2002; Bourdages et al., 2003; Ciliska et al., 2005; Shaw et al., 2006; Hogg and Hanley, 2008). Physician workload issues, lack of joint planning and challenges associated with multiple-stakeholder engagement deterred buy-in to collaboration by the PC sector (Arora et al., 2000; Banks-Smith et al., 2001; Gillam and Schamroth, 2002; Russell et al., 2003; Meyrick, 
2004; Chambers et al., 2005; Rothman et al., 2005). Finally, $\mathrm{PH}$ role confusion at the organizational level restricted collaboration, particularly with respect to the general lack of role clarity and variation in $\mathrm{PH}$ roles between sites (Meyrick, 2004; Hopayian et al., 2005).

\section{Knowledge and resource limitations}

Resource limitations were the most commonly identified organizational barrier to collaboration and included deficits in human and financial resources, space, team building and change management capacity (Carlisle et al., 2004; Chambers et al., 2005; Brauer et al., 2006; de Guzman, 2007). Concerns about human resources pertained to the availability and performance capacity of personnel to manage collaborative teams (Harrison and Keen, 2002; Iliffe and Lenihan, 2003; Hogg and Hanley, 2008), knowledge of PH concepts in PC (Arora et al., 2000; Heller et al., 2003; Hogg et al., 2006b) and skills required of PH to perform needs assessments (Jordan et al., 1998). The time needed for collaboration, community mobilization and evaluation was another barrier (Gillam et al., 1998; Harper et al., 2000; Harrison and Keen, 2002; Bourdages et al., 2003; Shandro, 2003). That said, many authors reported that health professionals facilitated collaboration (Jenkins and SullivanMarx, 1994; Ayres et al., 1996; Mayo et al., 1996; Jordan et al., 1998; Margolis et al., 2001; Harrison and Keen, 2002; Ferrari and Rideout, 2005; Hogg and Hanley, 2008) and partners brought resources to the table (Leeds et al., 2000; Wilson et al., 2000; Michener et al., 2005).

\section{Leadership, management and accountability issues}

Developing community-based committees with diverse membership mandated with an advisory or steering function was a key leadership approach to facilitate collaboration. Community engagement and representation on these committees were essential for collaborations to be responsive to community needs and facilitate joint planning (Machala and Miner, 1994; Alexy and Elnitsky, 1996; Billingham and Perkins, 1997; Crump et al., 1999; Ewles, 1999; Harper et al., 2000; Wilson et al., 2000; Bindman et al., 2001; Oros et al., 2001; Andrews, 2002; Michener et al., 2005; Rothman et al., 2005; Kaufman et al., 2006; Asaid and Riley, 2007; Sanders et al., 2008). Involvement of multiple professionals was also important to develop buy-in (Lambrew et al., 1993; Alexy and Elnitsky, 1996; Margolis et al., 2001; Iliffe et al., 2002; Shandro, 2003; Ciliska et al., 2005). Specific strategies to enable collaboration included: contractual agreements between jurisdictions and organizations (Wood et al., 1994; Lasker and The Committee on Medicine and Public Health, 1997; Cornell, 1999; Wilson et al., 2000; Porter et al., 2007; Wedel et al., 2007); organizational structures such as personnel designated to enhance cooperation between PC and PH (Lambrew et al., 1993; Gerrish, 1999; Williams et al., 1999; Headland et al., 2000); mentorship programs for new employees (Scott, 1999); involvement of someone able to bridge the sectors (Lasker and The Committee on Medicine and Public Health, 1997); physician and non-physician champions (Harper et al., 2000); and job descriptions requiring collaboration (Russell et al., 2003).

An important management process was to prepare the organization for changes associated with collaboration (The Network Towards Unity for Health, 2008) and ensure organizational structures and processes enabled healthcare providers to function optimally (Shandro, 2003; Ciliska et al., 2005; de Guzman, 2007). Small, stable, diverse teams with a high proportion of full-time staff enabled better team participation with more impact on patient care (Shaw et al., 2006; Xyrichis and Lowton, 2008). Obtaining adequate administrative support for managers (Lasker and The Committee on Medicine and Public Health, 1997; Kilduff et al., 1998) and assisting them to develop knowledge and skills needed to support the work of collaborative teams (Banks-Smith et al., 2001; Margolis et al., 2001) were stressed.

\section{Geographic proximity of partners}

Co-location of $\mathrm{PH}$ and $\mathrm{PC}$ organizations and team members was an important facilitator of collaboration. Geographic proximity of team members facilitated communication, information exchange, a sense of common purpose and high levels of trust between healthcare providers (Williams et al., 1999; Cook et al., 2001; Kaufman et al., 2006; Wedel et al., 2007; Xyrichis and Lowton, 2008). However, geographic separation of team members left some providers, especially in rural settings, feeling professionally isolated (Oros et al., 2001; Ciliska et al., 2005; Brown, 2006). Network formation is a strategy that created 
critical mass among geographically dispersed team members (Jewell and Griffiths, 2001).

\section{Shared protocols, tools and information sharing}

The use of a standardized shared system for collecting data and disseminating information enhanced access to quality medical information and supported effective interdisciplinary care (Voelker, 1994; Welton et al., 1997; Banks-Smith et al., 2001; Kaufman et al., 2006; Pierce et al., 2007; Stevenson Rowan et al., 2007; Wedel et al., 2007; The Network Towards Unity for Health, 2008). Shared protocols were useful for facilitating multi-disciplinary, evidence-based practice and quality assurance and for collecting data and disseminating information (Welton et al., 1997; Margolis et al., 2001; Hurst et al., 2002). Other facilitators of collaboration were evidence-based toolkits and decision-support tools (Rogers et al., 1999; Huston et al., 2006; Larson et al., 2006; Wedel et al., 2007), as well as clear referral processes between partners (Crump et al., 1999), and linked records (Shandro, 2003).

\section{Interactional factors}

\section{Shared purpose, philosophy and beliefs}

Early successes in the collaboration between PC and PH maintained enthusiasm (Cornell, 1999; Arora et al., 2000) and collaborations were enhanced if partners shared similar philosophies of care (Wiles and Robison, 1994; de Guzman, 2007); believed in the value of the collaboration's impact on community health (Cornell, 1999); and acknowledged the importance of health improvement and health inequalities (Arora et al., 2000). When there was not a similar philosophy of care or a common goal to reach, attitudes and beliefs of team members became barriers to collaboration. Attitudes included negative stereotypical views of PC and $\mathrm{PH}$ roles and a lack of belief in the value of collaboration or activities such as prevention (Voelker, 1994; Rogers et al., 1999; Russell et al., 2003; Porter et al., 2007; The Network Towards Unity for Health, 2008). Other attitudinal issues included resistance to change (Kilduff et al., 1998; Gerrish, 1999; Leeds et al., 2000; Banks-Smith et al., 2001; The Network Towards Unity for Health, 2008) and lack of interest in participating in planned activities (Bourdages et al., 2003; Chambers et al., 2005). A lack of understanding of PH (Billingham and Perkins, 1997;
Dion, 2004; Ciliska et al., 2005; Brauer et al., 2006; Xyrichis and Lowton, 2008) and various community nursing roles (Wiles and Robison, 1994; Baptiste and Drennan, 1999) created interpersonal barriers to collaboration, as did philosophical differences in approaches to care (Wiles and Robison, 1994; Hurst et al., 2002) and competing priorities and agendas (Harrison and Keen, 2002; Iliffe and Lenihan, 2003; Brauer et al., 2006).

\section{Clear roles and positive relationships}

The quality of professional relationships (Riley et al., 2003; PHRED, 2006; Harris et al., 2007; Jackson and Marley, 2007) was a vital facilitator for collaboration. Numerous authors reported on the importance of all partners having clear roles and responsibilities to enable effective teamwork (Wiles and Robison, 1994; Wood et al., 1994; Mayo et al., 1996; Billingham and Perkins, 1997; Lasker and The Committee on Medicine and Public Health, 1997; Welton et al., 1997; Gillam et al., 1998; Cook, 2000; Cook et al., 2001; Shandro, 2003; Dion, 2004; Ciliska et al., 2005; Brauer et al., 2006; Brown, 2006; Stevenson Rowan et al., 2007; Xyrichis and Lowton, 2008). Having better knowledge of one another's roles, skills and organizations enhanced the speed and nature of decision-making among teams.

Moreover, understanding of and capacity for interdisciplinary teamwork (Poulton, 2000; Heller et al., 2003; Dion, 2004; Xyrichis and Lowton, 2008) having had previous positive relationships and developing new linkages among $\mathrm{PC}$ and $\mathrm{PH}$ personnel (Wood et al., 1994; Ayres et al., 1996; Baptiste and Drennan, 1999; Margolis et al., 2001; Brown, 2006; Shaw et al., 2006; Porter et al., 2007) enabled collaborations. In contrast, various types of communication issues (Baptiste and Drennan, 1999; Hripcsak et al., 1999; Hurst et al., 2002; Ciliska et al., 2005) and poor rapport impeded collaboration (Wiles and Robison, 1994; Alexy and Elnitsky, 1996; Poulton, 2000; Harris et al., 2007; Hopayian et al., 2005). Specific strategies to develop team relations included the following: providing partners with feedback; acquiring input often; having patience to nurture relationships; taking the time needed to build linkages (Ferguson et al., 1992; Billingham and Perkins, 1997; McDonald et al., 1997; Mack et al., 2007); and education (Bennett et al., 1994; Scott, 1999; Ciliska et al., 2005). 


\section{Effective communication and decision-making strategies}

Many authors discussed the importance of direct and open communication and decision-making to promote understanding, trust and respect between PH, PC and the community (Lasker and The Committee on Medicine and Public Health, 1997; Welton et al., 1997; Kilduff et al., 1998; Cornell, 1999; Gerrish, 1999; Scott, 1999; Riley et al., 2003; Shirin and Absher, 2006; Asaid and Riley, 2007; Harris et al., 2007; Mack et al., 2007; Wedel et al., 2007). Brief, unscheduled visits were thought by some to overcome the frequently cited barriers of time and scheduling (Larson et al., 2006). Others identified the value of regular monthly meetings for promoting collaboration, enhancing communication and developing trust and mutual understanding (Margolis et al., 2001; Brown, 2006; Mack et al., 2007). Facilitators included attention to process, open, upfront communication about competition and control issues and appreciation of collaborating partners' various complementary resources, skills and expertise (Lasker and The Committee on Medicine and Public Health, 1997; Cornell, 1999; Michener et al., 2005). Involvement of the whole team was important to develop buy-in and a sense of ownership (Ferguson et al., 1992; Lasker and The Committee on Medicine and Public Health, 1997; Cornell, 1999; Leeds et al., 2000), while consensus building (Cook et al., 2001; Huston et al., 2006; Wedel et al., 2007) and joint planning (Oros et al., 2001) enabled teams to address various healthrelated activities. Specific strategies to improve communication and decision-making included: giving and receiving feedback (Billingham and Perkins, 1997; Asaid and Riley, 2007; Jackson and Marley, 2007); responding to community-identified needs (Rothman et al., 2005); being mindful of the PC context (Billingham and Perkins, 1997; Cornell, 1999); empowering all team members (Scott, 1999); and letting go of rigid professional boundaries to better meet community needs (Lasker and The Committee on Medicine and Public Health, 1997; Riley et al., 2003; Ciliska et al., 2005).

\section{Markers of successful collaboration}

Overall, there was sparse evidence about what marks successful collaboration between PC and $\mathrm{PH}$. Although authors did not specifically discuss indicators, some were surmized from the extractions.
Successful collaboration was thought to have occurred when there was: a feeling of being part of the team (Wiles and Robison, 1994); full co-location of the team (Wedel et al., 2007); improvement in health-related outcomes (Porter et al., 2007); reduction in health disparities (Porter et al., 2007); improvement in access to health services (Porter et al., 2007); improvement in healthrelated knowledge, attitudes and or behaviors (Porter et al., 2007); increased capacity and expertise (Desai et al., 2003); implementation of new collaborative initiatives (Desai et al., 2003); sustained programs (Riley et al., 2003; Wedel et al., 2007); increased understanding of PC (Gillam and Schamroth, 2002); increased community assessment and data collection and analysis skills (Gillam and Schamroth, 2002); increased linkages with other agencies (Gillam and Schamroth, 2002); and improved support for multidisciplinary collaboration and teamwork (Gillam and Schamroth, 2002).

\section{Positive outcomes of collaboration}

Our review found that successful collaboration between PC and PH could have different benefits for each partner (Lasker and The Committee on Medicine and Public Health, 1997) and resulted in outcomes for individuals and populations, health professionals and healthcare systems.

\section{Individuals and populations}

Health outcomes for individuals and populations can be grouped into three main areas beginning with improvements in chronic disease management (Crump et al., 1999; Record et al., 2000; Desai et al., 2003; Jackson and Marley, 2007; McElmurry et al., 2009), including screening (Gillam et al., 1998; Rothman et al., 2005; Larson et al., 2006) and self-care (McElmurry et al., 2009). Second, there were improvements in communicable disease control (Mayo et al., 1996; Danila et al., 1997; Hripcsak et al., 1999; Hogg et al., 2006a) and immunization rates (Bennett et al., 1994; Crump et al., 1999; Rothman et al., 2005; Larson et al., 2006). Third, improvements were seen in maternal and child health including better birth outcomes (Machala and Miner, 1994), reduced teen pregnancies (Rothman et al., 2005), increased uptake of prenatal care (Rothman et al., 2005), healthier maternal and child lifestyles (Margolis et al., 2001) and reduced child emotional and behavioral problems (Sanders et al., 2008). 


\section{Health professionals}

Outcomes for health professionals included enhanced educational experiences for students (Mayo et al., 1996; Wilson et al., 2000; Oros et al., 2001) and development of new academic programs (Williams et al., 1999; Roff, 2003). At the practice level, there were improvements in the understanding of PC and PH concepts, areas of responsibility and roles (Cornell, 1999; Headland et al., 2000; Leeds et al., 2000; Cook et al., 2001; Heller et al., 2003; Morgan and Kelly, 2004), team functioning (Gerrish, 1999; Leeds et al., 2000; Andrews, 2002; Riley et al., 2003) and information sharing (Wood et al., 1994; Banks-Smith et al., 2001; Kaufman et al., 2006).

\section{Health service delivery}

At the health service delivery level, the most frequent outcome was improved access to care (Ferguson et al., 1992; Lasker and The Committee on Medicine and Public Health, 1997; Lundeen et al., 1997; Leeds et al., 2000; Banks-Smith et al., 2001; Oros et al., 2001; Rothman et al., 2005; Harrison et al., 2006; Kaufman et al., 2006; PHRED, 2006; Shirin and Absher, 2006; McElmurry et al., 2009) and quality of care (Jenkins and SullivanMarx, 1994; Wood et al., 1994; Malcolm and Barnett, 1995; Lasker and The Committee on Medicine and Public Health, 1997; Headland et al., 2000; Banks-Smith et al., 2001; Kaufman et al., 2006; Wedel et al., 2007). Other outcomes were improved efficiencies through timelier case reporting and less duplication of care (Malcolm and Barnett, 1995; Hripcsak et al., 1999; Headland et al., 2000; Cook et al., 2001; Margolis et al., 2001; Dion, 2004), enhanced individual patient and community satisfaction (Wood et al., 1994; Leeds et al., 2000; Kearney et al., 2005; Lea et al., 2005; Wedel et al., 2007) and improved continuity and coordination of care (Shandro, 2003; PHRED, 2006; Shirin and Absher, 2006). Care delivery processes were strengthened by an increased focus on health promotion and illness prevention (Lasker and The Committee on Medicine and Public Health, 1997; Banks-Smith et al., 2001; Lemelin et al., 2001; Iliffe and Lenihan, 2003; Riley et al., 2003; Morgan and Kelly, 2004; Kearney et al., 2005) and population health needs (Renfrew et al., 2001; Dion, 2004; Morgan and Kelly, 2004), use of needs assessments in PC (Danila et al., 1997; Lasker and The Committee on Medicine and Public Health, 1997; Jordan et al., 1998; Cornell, 1999; Banks-Smith et al., 2001; Cook et al., 2001; Hurst et al., 2002) and support for quality improvement (Danila et al., 1997; Lasker and The Committee on Medicine and Public Health, 1997; Harrison and Keen, 2002; Hurst et al., 2002; Desai et al., 2003). Cost outcomes included increased funding support and enhanced sustainability as a result of collaboration among formerly competing organizations (Oros et al., 2001; Kaufman et al., 2006; de Guzman, 2007) and efficiencies through resource sharing (Ferguson et al., 1992; Banks-Smith et al., 2001; Cook et al., 2001).

\section{Negative outcomes of collaboration}

There were also some negative outcomes and risks associated with collaboration between PC and $\mathrm{PH}$ including reservations about the gains to be made given the modest evidence base (Hurst et al., 2002; Stevenson Rowan et al., 2007) and cost (Andrews, 2002). Benefits to individuals and populations were not always realized (Wood et al., 1994; Gillam and Schamroth, 2002) and the extent to which team members felt part of the team varied (Wiles and Robison, 1994; McDonald et al., 1997; Baptiste and Drennan, 1999; Cook et al., 2001). Questions remain about how to provide $\mathrm{PH}$ leadership in PC (Brown et al., 2007) and concerns that PH skills might be spread too thinly (Marks and Hunter, 2005). Financial incentives to achieve health promotion targets can conflict with professional philosophies and be demoralizing when they shape practice in a way that shifts care away from local priorities and ignores inequities (Marks and Hunter, 2005).

For PC, the values underpinning collaboration with $\mathrm{PH}$ and a community-oriented approach can be at odds especially with traditional medical training (Gillam and Schamroth, 2002; Stevenson Rowan et al., 2007). There is risk too that the time PC providers have for patient care will be diminished as a result of the time needed to collaborate with other professionals (McDonald et al., 1997). For PH, dispersal of PH staff into PC settings can lead to a lack of critical mass, risking erosion of $\mathrm{PH}$ expertise (CIHR, 2003). Added to this, there is uncertainty whether collaboration with PC has the potential to address a broad $\mathrm{PH}$ agenda and questions about the current capacity of $\mathrm{PH}$ organizations to apply $\mathrm{PH}$ skills in PC (Heller et al., 2003). 


\section{Discussion}

The purpose of this scoping literature review was to determine the structures and processes required to build successful collaborations between $\mathrm{PH}$ and PC and the outcomes and markers of these collaborations to inform a program of research focused on strengthening PHC through collaboration between these sectors. The review revealed that successful collaboration was thought to have occurred when there were positive systems, organizational or interactional changes. At the system level, collaboration was successful with improvement in health-related outcomes, reduction in health disparities and improvement in access to health services (Porter et al., 2007). At the organizational level, collaboration was successful with a feeling of being part of the team (Wiles and Robison, 1994), full co-location of the team (Wedel et al., 2007), implementation of new collaborative initiatives (Desai et al., 2003) and sustained programs (Riley et al., 2003; Wedel et al., 2007). At the interactional level, collaboration was successful with improvement in health-related knowledge, attitudes and or behaviors (Porter et al., 2007) and increased capacity and expertise (Desai et al., 2003). As such, there is evidence to support collaboration between $\mathrm{PC}$ and $\mathrm{PH}$ as a strategy to address principles of equity and access in health care and enhance the potential for achieving the goal of 'health for all' (WHO, 2008). Attention to the structural and process factors that impede and facilitate collaboration between these sectors is likely to be worthwhile and requires the efforts of policymakers, managers and healthcare providers.

At a systems level, strong leadership from policymakers is needed to create policies that support collaboration, reduce the silos between $\mathrm{PC}$ and $\mathrm{PH}$ and enable enhanced communication and cooperation within and between levels of government. The use of alternative funding mechanisms to remunerate $\mathrm{PC}$ physicians and provide incentive to collaborate with $\mathrm{PH}$ was advocated by some authors of articles in our review. However, a recent article reviewing the use of financial incentives to promote $\mathrm{PH}$ activities in $\mathrm{PC}$ in the United Kingdom found that incentivizing activities may lead to negative health outcomes and further health inequities (Peckham and Hann, 2008). This calls into question whether alternative funding mechanisms necessarily are an enabler of collaboration that will result in improved health for populations. Another major systems level barrier to collaboration between PC and $\mathrm{PH}$ is the lack of sustainable funding available to support service providers to participate in collaboration as well as the lack of funding for information systems and evaluation. This is consistent with findings from a narrative review of Comprehensive Primary Health Care in Australia which concluded that for the model to be realized 'resources will need to be directed beyond individual treatment to population health issues, cross-sector collaboration and consumer participation' (Hurley et al., 2010: 147).

At an organizational level, managers and senior administrators have a significant role to play in fostering $\mathrm{PC}$ and $\mathrm{PH}$ collaboration by striving to achieve a unified vision and goals and a shared understanding and valuing of the unique cultures and contributions of both sectors. Leadership is also required at this level particularly with respect to facilitating joint planning between $\mathrm{PC}$ and $\mathrm{PH}$ and the community. Community participation in health is a principle of PHC that has been difficult to achieve. A recent review of community-oriented PC, an approach developed more than 50 years ago for PC physicians to address community health found that full implementation of the model with community engagement and participation in PC practices was rare (Gavagan, 2008). At the interactional level, our review suggests that service providers within an organization have a key role to play to enable collaboration between PC and $\mathrm{PH}$. Working together to achieve open consistent communication and strong interprofessional relationships with a clear understanding of the roles of $\mathrm{PC}$ and $\mathrm{PH}$ team members is particularly important. Writing about the Australian experience, McDonald et al. (2009) identify that coordinated and integrated primary and community care is enhanced by interorganizational and interprofessional partnerships.

This scoping review aimed to capture contextfree, context-sensitive and colloquial evidence (Culyer and Lomas, 2006) about the structures, processes and outcomes of this collaboration. By casting such a wide net, the results of our initial search strategy yielded many more articles than we had anticipated, a phenomenon we believe occurred because of the overlap in our focus of interest with closely related areas such as community

Primary Health Care Research \& Development 2012; 13: 327-346 
intervention research, health promotion and community participation. Moreover, it was difficult to discern between collaboration and other similar processes such as cooperation, coordination and integration. This made the review process challenging and resource intensive (Valaitis et al., in press). Many articles described collaborations initiated by universities responding to unmet health needs in a locality through service learning opportunities for students. Our review did not include educational literature and further research should be carried out to understand the training required to enable $\mathrm{PC}$ and $\mathrm{PH}$ collaboration.

The review provides a broad overview of the characteristics of collaboration between PC and $\mathrm{PH}$. It provides the foundations of a framework from which our ongoing research can develop a more complex understanding of when, where and under what contextual conditions collaboration is effective and when it warrants time and financial resources. Clearly, there are considerable structural and process-based factors impacting collaboration at systemic, organizational and interactional levels. What is less clear is how these factors interrelate and influence one another. Moreover, questions remain as to which factors are necessary but not sufficient for collaboration and which compilation of factors is sufficient to create a successful collaboration. Our review indicates that $\mathrm{PC}$ and $\mathrm{PH}$ collaborations involve various health professionals practicing in diverse models of care and geographic and social contexts. All of these factors influence PC and $\mathrm{PH}$ collaboration. For example, some PC models are likely more enabling of collaboration than others (Lamarche et al., 2003) and in rural settings collaboration may be necessitated by a smaller resource base. Future research should explore these relationships and interactions.

Across countries, most collaboration between $\mathrm{PC}$ and PH was initiated and implemented at a local level, reflecting the grass roots nature of innovation and change. Unmet health needs and gaps in health services would undoubtedly be more visible at a local level generating a response by concerned stakeholders. The leadership and risk-taking inherent in local efforts provides a starting point and potential lever for broader change. However, this review shows that it is important for countries and organizations to have policy supports and resources in place to facilitate the development, evaluation and sustainability of collaboration if the impact of collaboration is intended to extend beyond a local level and a reliance on the good will of those involved.

This scoping review includes a large proportion of articles that are descriptive accounts of collaboration. Furthermore, of the 34 articles reporting results from research studies, $75 \%$ used qualitative, cross-sectional survey or mixed methods designs. Although these designs limit what can be concluded about the outcomes of collaboration, the benefits of collaboration between $\mathrm{PC}$ and $\mathrm{PH}$, particularly in chronic disease management, communicable disease control and maternal child health, cannot be discounted. Just as importantly, potential risks and costs of collaboration for both PC and PH require careful consideration. The conditions and contexts in which potential gains from successful collaborative synergies outweigh associated risks and costs need further exploration.

More primary research and development of theoretical constructs and frameworks are needed to develop the science and inform the practice of successful collaboration between PC and PH. Our ongoing program of research will build on the results of this scoping review by investigating collaboration between PC and PH in the Canadian context, developing a framework and drafting indicators of successful collaboration. It is the first study in a four-year program of research (http:// strengthenPHC.mcmaster.ca) that aims to understand how PHC can be strengthened through collaboration between $\mathrm{PC}$ and $\mathrm{PH}$, what types of collaboration are best suited for particular contexts, the indicators of collaboration and when collaboration makes the most sense.

\section{Acknowledgments}

We sincerely thank the following sponsors for their financial and in-kind support for this program of research: the Canadian Health Services Research Foundation; Health Services and Policy Research Support Network (HSPRSN) Partnership Program; the Michael Smith Foundation for Health Research; McMaster University, School of Nursing and the Faculty of Health Sciences; the Public Health Agency of Canada; Huron County Health Unit; Victorian Order of Nurses Canada; 
Registered Nurses' Association of Ontario; Capital District Health Authority, Nova Scotia; Canadian Alliance of Community Health Centres Association; Somerset West Community Health Centre (SWCHC); Canadian Public Health Association; and Hamilton Niagara Haldimand Brant Local Health Integration Network.

\section{References}

Alexy, B.B. and Elnitsky, C.A. 1996: Community outreach: rural mobile health unit. Journal of Nursing Administration 26, 38-42.

Anderson, K., Sebaldt, R., Lohfeld, L., Karwalajtys, T., Ismaila, A., Goeree, R., Donald, F., Burgess, K. and Kaczorowski, J. 2008: Patient views on reminder letters for influenza vaccinations in an older primary care patient population: a mixed methods study. Canadian Journal of Public Health 99, 133-36.

Andrews, D. 2002: Management of HIV/AIDS on the mid north coast: a collaborative model of care involving general practitioners and the public health system. Australian Journal of Rural Health 10, 244-48.

Arksey, H. and O'Malley, L. 2005: Scoping studies: towards a methodological framework. International Journal of Social Research Methodology 8, 19-32.

Arora, S., Davies, A. and Thompson, S. 2000: Developing health improvement programmes: challenges for a new millennium. Journal of Interprofessional Care 14, 9-18.

Asaid, A. and Riley, K. 2007: From solo practice to partnering - the evolution of the Elmore model of primary health. Australian Family Physician 36, 167-69.

Ayres, P.J., Pollock, C.T., Wilson, A., Fox, P., Tabner, T. and Hanney, I. 1996: Practical public health in a primary care setting. Discrete projects confer discrete benefits but a long-term relationship is needed. Journal of Management in Medicine 10, 36-48.

Banks-Smith, J., Dowswell, T., Gillam, S. and Shipman, C. 2001: Primary care groups and trusts. Nursing Times 97, 30-32.

Baptiste, L. and Drennan, V. 1999: Research study. Communication between school nurses and primary care teams. British Journal of Community Nursing 4, 13-18.

Bennett, N.M., Lewis, B., Doniger, A.S., Bell, K., Kouides, R., LaForce, F.M. and Barker, W. 1994: A coordinated, communitywide program in Monroe County, New York, to increase influenza immunization rates in the elderly. Archives of Internal Medicine 154, 1741-45.

Billingham, K. and Perkins, E. 1997: A public health approach to nursing in the community. Nursing Standard 11, 43-46.

Bindman, A.B., Weiner, J.P. and Majeed, A. 2001: Primary care groups in the United Kingdom: quality and accountability. Health Affairs 20, 132-45.

Bourdages, J., Sauvageau, L. and Lepage, L. 2003: Factors in creating sustainable intersectoral community mobilization for prevention of heart and lung disease. Health Promotion International 18, 135-44.

Brauer, P., Schneider, T., Preece, C., Northmore, D., West, E., Dietrich, L. and Davidson, B. 2006: Promoting healthy lifestyles in Ontario Family Health Networks. Canadian Journal of Dietetic Practice and Research 67 (Suppl), S39-46.

Brown, C. and van Zwanenberg, T.D. 1989: Primary and community health services in Newcastle upon Tyne - a joint statement of intent. Journal of the Royal College of General Practitioners 39, 164-65.

Brown, H.M. 2006: Towards effective teamwork: an examination of the perceptions of interprofessional teamwork and continuing education needs amongst primary health care providers in rural Newfoundland. Dissertation/thesis. Newfoundland: Memorial University of Newfoundland.

Brown, S., Burns, D., Chapel, H., Cronin, D., Evans, D., Gray, S., Howard, J., Kendall, L., Lewendon, G., Mackenzie, I., Miles, D., Morgan, K., Orme, J., Tolley, F. and Weil, S. 2007: Public health leadership in the real world: the role of the director of public health. Public Health Medicine 6, 58-60.

Butler-Jones, D. 2004: Primary health reform and public health. Public Health Agency of Canada. Retrieved on August 31, 2008 from http://www.phac-aspc.gc.ca/publicat/ pmr_spr/

Carlisle, R., Morris, R., Whittle, S., Hargreaves, S., Fryers, P. and Lindley, S. 2004: The health impact of changing to geographical working. Community Practitioner 77, 376-80.

Chambers, L.W., Kaczorowski, J., Dolovich, L., Karwalajtys, T., Hall, H.L., McDonough, B., Hogg, W., Farrell, B., Hendriks, A. and Levitt, C. 2005: A community-based program for cardiovascular health awareness. Canadian Journal of Public Health 96, 294-98.

Canadian Institutes of Health Research (CIHR) - Institute of Population and Public Health. 2003: The Future of public health in Canada: developing a public health system for the 21st century. Ottawa, ON: Canadian Institutes of Health Research.

Ciliska, D., Ehrlich, A. and DeGuzman, A. 2005: Public health and primary care: challenges and strategies for collaboration. Hamilton, ON: Public Health Research, Education and Development Programme.

Ciliska, D., Woodcox, V. and Isaacs, S. 1992: A descriptive study of the attachment of public health nurses to family physicians' offices. Public Health Nursing 9, 53-57.

Cook, G., Gerrish, K. and Clarke, C. 2001: Decision-making in teams: issues arising from two UK evaluations. Journal of Interprofessional Care 15, 141-51.

Cook, L. 2000: Triple integration nursing. Nursing Standard 14, 33-34.

Cornell, S. 1999: Public health and primary care collaboration a case study. Journal of Public Health 21, 199-204.

Crump, R.L., Gaston, M.H. and Fergerson, G. 1999: HRSA's Models That Work Program: implications for improving access to primary health care. Public Health Reports 114, 218-24.

Primary Health Care Research \& Development 2012; 13: 327-346 
Culyer, A.J. and Lomas, J. 2006: Deliberative processes and evidence-informed decision making in healthcare: do they work and how might we know? Evidence and Policy: A Journal of Research, Debate and Practice 2, 357-71.

Danila, R.N., Lexau, C., Lynfield, R., Moore, K.A. and Osterholm, M.T. 1997: Addressing emerging infections. The partnership between public health and primary care physicians. Postgraduate Medicine 106, 90-92.

Dault, M., Lomas, J. and Barer, M. 2004: Listening for direction II: National consultation on health services and policy issues for 2004-2007 Final Report. Ottawa: Canadian Health Services Research Foundation and Canadian Institutes of Health Research.

DeGuzman, A. 2007: Facilitators and barriers in the implementation of nurse practitioner roles in public health units in Ontario. Hamilton, Ontario: McMaster University.

Desai, J., Solberg, L., Clark, C., Reger, L., Pearson, T., Bishop, D., Roberts, M., Sniegowski, R. and O'Connor, P. 2003: Improving diabetes care and outcomes: the secondary benefits of a public health-managed care research collaboration. Journal of Public Health Management and Practice 9 (Suppl. 16), S36-43.

Dion, X. 2004: A multidisciplinary team approach to public health working. British Journal of Community Nursing 9, $149-54$.

Edmonstone, J., Hamer, S. and Smith, S. 2003: Integrated community nursing teams: an evaluation study. Community Practitioner 76, 386-89.

Elster, A.B., Callan, C.M. and American Medical Association. 2002: Physician roles in medicine-public health collaboration: future directions of the American Medical Association. American Journal of Preventive Medicine 22, 211-13.

Ewles, L. 1999: Health improvement programmes. Avon calling. Health Service Journal 109, 24-25.

Fatchett, A.B. 1990: Health visiting: a withering profession? Journal of Advanced Nursing 15, 216-22.

Ferguson, M.G., Berkeley, L., Fourcher, L., Guyton, B. and Reiner, L.R. 1992: Health Care Linkage Project: improving access to care. Henry Ford Hospital Medical Journal 40, 9-12.

Ferrari, A. and Rideout, B. 2005: The collaboration of public health nursing and primary care nursing in the development of a nurse managed health center. Nursing Clinics of North America 40, 771-78.

Fraser, J. 2005: Population and public health in Australian general practice - changes, challenges and opportunities. Australian Family Physician 34, 177-79.

Frenk, J. 2009: Reinventing primary health care: the need for systems integration. Lancet 374, 170-73.

Gavagan, T. 2008: A systematic review of COPC: evidence for effectiveness. Journal of Health Care for the Poor and Underserved 19, 963-80.

Gerrish, K. 1999: Teamwork in primary care: an evaluation of the contribution of integrated nursing teams. Health and Social Care in the Community 7, 367-75.

Gillam, S., Joffe, M., Miller, R., Gray, A., Epstein, L. and Plamping, D. 1998: Community-oriented primary care - old wine in new bottles. Journal of Interprofessional Care 12, 53-61.

Gillam, S. and Schamroth, A. 2002: The community-oriented primary care experience in the United Kingdom. American Journal of Public Health 92, 1721-25.

Harper, P.G., Baker, N.J. and Reif, C.J. 2000: Implementing community-oriented primary care projects in an urban family practice residency program. Family Medicine 32, 683-90.

Harris, K., Pickering, L., Fasano, N., Fowler, G., Gangarosa, P. and Gust, D. 2007: Relationships between state health departments and medical professional organizations regarding immunizations. Journal of Public Health Management and Practice 13, 590-94.

Harris, S.K., Samples, C.L., Keenan, P.M., Fox, D.J., Melchiono, M.W. and Woods, E.R. 2003: Outreach, mental health, and case management services: can they help to retain HIV-positive and at-risk youth and young adults in care? Maternal and Child Health Journal 7, 205-18.

Harrison, R.L., MacNab, A.J., Duffy, D.J. and Benton, D.H.J. 2006: Brighter smiles: service learning, inter-professional collaboration and health promotion in a First Nations community. Canadian Journal of Public Health 97, 237-40.

Harrison, S. and Keen, S. 2002: Public health practitioners in NHS hospital trusts: the impact of 'medical care epidemiologists'. Journal of Public Health Medicine 24, 16-20.

Headland, C., Crown, N. and Pringle, M. 2000: Specialist nursing. Integrated nursing in primary care and analysis of nurses' caseloads. British Journal of Nursing 9, 708-12.

Heller, B.R. and Goldwater, M.R. 2004: The Governor's Wellmobile: Maryland's mobile primary care clinic. Journal of Nursing Education. 43, 92-94.

Heller, R.F., Edwards, R., Patterson, L. and Elhassan, M. 2003: Public health in Primary Care Trusts: a resource needs assessment. Public Health 117, 157-64.

Hogg, R. and Hanley, J. 2008: Community development in primary care: opportunities and challenges. Community Practitioner 81, 22-25.

Hogg, W., Huston, P., Martin, C., Saginur, R., Newbury, A., Vilis, E. and Soto, E. 2006a: Promoting best practices for control of respiratory infections: collaboration between primary care and public health services. Canadian Family Physician 52, 1110-11.

Hogg, W., Huston, P., Martin, C. and Soto, E. 2006b: Enhancing public health response to respiratory epidemics: are family physicians ready and willing to help? Canadian Family Physician 52, 1254-60.

Hopayian, K., Harvey, I., Howe, A. and Horrocks, G. 2005: Perceived aids and barriers to clinical effectiveness in the work of primary care organisations in England: a qualitative study. Quality in Primary Care 13, 17-24.

Hripcsak, G., Knirsch, C.A., Jain, N.L., Stazesky, R.C. Jr, Pablos-Mendez, A. and Fulmer, T. 1999: A health information network for managing innercity tuberculosis: bridging clinical care, public health, and home care. Computers and Biomedical Research 32, 67-76. 
Hurley, C., Baum, F., Johns, J. and Labonte, R. 2010: Comprehensive primary health care in Australia: findings from a narrative review of the literature. Australasian Medical Journal 1, 147-52.

Hurst, K., Ford, J. and Gleeson, C. 2002: Evaluating self-managed integrated community teams. Journal of Management in Medicine 16, 463-83.

Huston, P., Hogg, W., Martin, C., Soto, E. and Newbury, A. 2006: A process evaluation of an intervention to improve respiratory infection control practices in family physician offices. Canadian Journal of Public Health 97, 475-79.

Hutchison, B., Abelson, J. and Lavis, J. 2001: Primary care in Canada: so much innovation, so little change. Health Affairs 20, 116-31.

Hutchison, B. 2008: A long time coming: primary healthcare renewal in Canada. Healthcare Papers 8, 10-24.

Iliffe, S. and Lenihan, P. 2003: Integrating primary care and public health: learning from the community-oriented primary care model. International Journal of Health Servey 33, 85-98.

Iliffe, S., Lenihan, P., Wallace, P., Drennan, V., Blanchard, M. and Harris, A. 2002: Applying community-oriented primary care methods in British general practice: a case study. The British Journal of General Practice: The Journal of the Royal College of General Practitioners 52, 646-51.

Jackson, C.L. and Marley, J.E. 2007: A tale of two cities: academic service, research, teaching and community practice partnerships delivering for disadvantaged Australian communities. Medical Journal of Australia 187, 84-87.

Jenkins, M.L. and Sullivan-Marx, E.M. 1994: Nurse practitioners and community health nurses. Clinical partnerships and future visions. Nursing Clinics of North America 29, 459-70.

Jewell, T. and Griffiths, S. 2001: Shifting the balance of power and managed public health networks. Public Health Medicine 3, 45-47.

Joint Task Group on Public Health Human Resources. 2005: Building the public health workforce: a Pan-Canadian framework for public health human resource planning. Retrieved 31 August 2008 from http://www.phac-aspc. gc.ca/php-psp/pdf/building_the_public_health_workforce_fo_ \%20the-21stc_e.pdf

Jordan, J., Wright, J., Wilkinson, J. and Williams, R. 1998: Assessing local health needs in primary care: understanding and experience in three English districts. Quality in Health Care 7, 83-89.

Kaufman, A., Derksen, D., Alfero, C., DeFelice, R., Sava, S., Tomedi, A., Baptiste, N., Jaeger, L. and Powell, W. 2006: The Health Commons and care of New Mexico's uninsured. Annals of Family Medicine 4 (Suppl. 1), S22-27.

Kearney, M., Bradbury, C., Ellahi, B., Hodgson, M. and Thurston, M. 2005: Mainstreaming prevention: prescribing fruit and vegetables as a brief intervention in primary care. Public Health 119, 981-86.

Kilduff, A., McKeown, K. and Crowther, A. 1998: Health needs assessment in primary care: the evolution of a practical public health approach. Public Health 112, 175-81.

Primary Health Care Research \& Development 2012; 13: 327-346
Koponen, P. and Kalkas, H. 1997: Practice patterns of Finnish public health nurses. International Journal of Nursing Practice 3, 97-104.

Lamarche, P.A., Beaulieu, M., Pinealut, R., Contandriopoulos, A., Denis, J. and Haggery, J. 2003: Choices for change: the path for restructuring primary healthcare services in Canada. Retrieved 28 August 2008 from http://www.chsrf.ca/Migrated/ PDF/ResearchReports/CommissionedResearch/choices_for_ change_e.pdf

Lambrew, J.M., Ricketts, T.C. III. and Morrissey, J.P. 1993: Case study of the integration of a local health department and a community health center. Public Health Reports 108, 19-29.

Larson, K., Levy, J., Rome, M.G., Matte, T.D., Silver, L.D. and Frieden, T.R. 2006: Public health detailing: a strategy to improve the delivery of clinical preventive services in New York City. Public Health Reports 121, 228-34.

Lasker, R.D. 2002: Maximizing the power of partnerships: a team-based workshop. In Community Campus Partnerships for Health Conference, Miami, FL, May 4, 2002, pp. 2-10.

Lasker, R.D. and The Committee on Medicine and Public Health. 1997: Medicine and public health. The power of collaboration. New York: New York Academy of Medicine.

Lea, D.H., Johnson, J.L., Ellingwood, S., Allan, W., Patel, A. and Smith, R. 2005: Telegenetics in Maine: successful clinical and educational service delivery model developed from a 3-year pilot project. Genetics in Medicine 7, 21-27.

Lemelin, J., Hogg, W. and Baskerville, N. 2001: Evidence to action: a tailored multifaceted approach to changing family physician practice patterns and improving preventive care. Canadian Medical Association Journal 164, 757-63.

Lundeen, S.P., Friedbacher, B., Thomas, M. and Jackson, T. 1997: Testing the viability of collaborative interdisciplinary practice in community-focused primary health care: a case study in change. Wisconsin Medical Journal 96, 30-36.

Machala, M. and Miner, M.W. 1994: Money isn't everything: rural physicians identify other factors that facilitate providing prenatal care for low-income women. Public Health Reports 109, 441-45.

Mack, D., Brantley, K.M. and Bell, K.G. 2007: Mitigating the health effects of disasters for medically underserved populations: electronic health records, telemedicine, research, screening, and surveillance. Journal of Health Care for the Poor and Underserved 18, 432-42.

Malcolm, L. and Barnett, P. 1995: Decentralisation, integration and accountability: perceptions of New Zealand's top health service managers. Health Services Management Research 8, 121-34.

Margolis, P.A., Stevens, R., Bordley, W.C., Stuart, J., Harlan, C., Keyes-Elstein, L. and Wisseh, S. 2001: From concept to application: the impact of a community-wide intervention to improve the delivery of preventive services to children. Pediatrics 108, e42, pp. 1-10.

Marks, L. and Hunter, D.J. 2005: Moving upstream or muddying the waters? Incentives for managing for health. Public Health 119, 974-80. 
Mayo, K., White, S., Oates, S.K. and Franklin, F. 1996: Community collaboration: prevention and control of tuberculosis in a homeless shelter. Public Health Nursing $13,120-27$.

McDonald, A.L., Langford, I.H. and Boldero, N. 1997: The future of community nursing in the United Kingdom: district nursing, health visiting and school nursing. Journal of Advanced Nursing 26, 257-65.

McDonald, J., Powell Davies, G. and Fort Harris, M. 2009: Interorganisational and interprofessional partnership approaches to achieve more coordinated and integrated primary and community health services: The Australian experience. Australian Journal of Primary Health 15, 262-69.

McElmurry, B.J., McCreary, L.L., Park, C.G., Ramos, L., Martinez, E., Parikh, R., Kozik, K. and Fogelfeld, L. 2009: Implementation, outcomes, and lessons learned from a collaborative primary health care program to improve diabetes care among urban Latino populations. Health Promotion Practice, 10, 293-302.

Meyrick, J. 2004: View from the front: three key challenges facing Public Health in one London Primary Care Trust. Public Health Medicine 5, 67-71.

Michener, J.L., Champagne, M.T., Yaggy, D., Yaggy, S.D. and Krause, K.M. 2005: Making a home in the community for the academic medical center. Academic Medicine 80, 57-61.

Morgan, S. and Kelly, P.M. 2004: Enhancing the population health capacity of general practice: an innovative training model for general practice registrars. Australian Family Physician 33, 473-74.

Muldoon, L.K., Hogg, W.E. and Levitt, M. 2006: Primary care (PC) and primary health care (PHC) - What is the difference? Canadian Journal of Public Health - Revue Canadienne de Sante Publique 97, 409-11.

Naylor, D., Basrur, S., Bergeron, M., Brunham, R., Butler-Jones, D., Dafoe, G., Ferguson-Pare, M., Lussing, F., McGeer, A., Neufeld, K. and Plummer, F. 2003: Learning from SARS: renewal of public health in Canada. Ottawa: Health Canada.

O'Neil, M. and Clarkson, H. 2002: "Reaching families with young children": a community dental health project for preventing early childhood caries. Probe 36, 145-48.

Olney, R.S. and Yoon, P.W. 2007: Role of family medical history information in pediatric primary care and public health: introduction. Pediatrics 120 (Suppl. 9), S57-59.

Ontario Ministry of Health and Long Term Care. 2006: Revitalizing Ontario's public health capacity: the final report of the Capacity Review Committee. Retrieved 31 August 2008 from http://www.health.gov.on.ca/english/ public/pub/ministry_reports/capacity_review06/capacity_ review06.pdf

Oros, M., Johantgen, M., Antol, S., Heller, B.R. and Ravella, P. 2001: Community-based nursing centers: a model for health care delivery in the 21st century. Community-based nursing centers: challenges and opportunities in implementation and sustainability. Policy, Politics, and Nursing Practice 2, 277-87.
Peckham, S. and Hann, A. 2008: General practice and public health: assessing the impact of the new GMS contract. Critical Public Health 18, 347-56.

Pierce, R., Pittard, A., West, T. and Richardson, M. 2007: Medical response to hurricanes Katrina and Rita: local public health preparedness in action. Journal of Public Health Management and Practice 13, 441-46.

Porter, P.G., Ross, L., Chapman, R.W., Kohatsu, N.D. and Fox, P. 2007: Medicine and public health partnerships: predictors of success. San Francisco, CA: Institute for Health and Aging, University of California.

Poulton, B. 2000: Reorganising primary care: the Northern Ireland approach. Primary Health Care 10, 10-14.

Public Health Agency of Canada. 2007: Core competencies for public health in Canada [Release 1.0]. Ottawa: Public Health Agency of Canada.

Public Health Research Education and Development (PHRED) Program Sudbury and District Health Unit. 2006: Evaluation of the prenatal and postnatal nurse practitioner services initiative: final report. Sudbury: PHRED Program, Sudbury and District Health Unit.

QSR International Pty Ltd. 2008. NVivo qualitative data analysis software, Version 8. Cambridge, MA: QSR International Pty Ltd.

Rachlis, M. 2006: Public health and primary care collaboration. Toronto: Public Health Agency of Canada.

Record, N.B., Harris, D.E., Record, S.S., Gilbert-Arcari, J., Desisto, M. and Bunnell, S. 2000: Mortality impact of an integrated community cardiovascular health program. American Journal of Preventive Medicine 19, 30-38.

Renfrew, B.L., Kempe, A., Lowery, N.E., Chandramouli, V., Steiner, J.F. and Berman, S. 2001: The impact of immunization record aggregation on up-to-date rates implications for immunization registries in rural areas. Journal of Rural Health 17, 122-26.

Riley, A.J., Harding, G., Meads, G., Underwood, M.R. and Carter, Y.H. 2003: An evaluation of personal medical services: the times they are achangin. Journal of Interprofessional Care 17, 127-39.

Roff, M. 2003: Levelling the playing fields of England: promoting health in deprived communities. Journal of the Royal Society of Health 123, 20-22.

Rogers, W., Veale, B. and Weller, D. 1999: Evaluation of the interface between general practice and population health in research funded by the General Practice Evaluation Program. Australian Journal of Primary Health - Interchange 5, 51-54.

Rothman, N.L., Lourie, R.J., Brian, D. and Foley, M. 2005: Temple Health Connection: a successful collaborative model of community-based primary health care. Journal of Cultural Diversity 12, 145-51.

Rumrill, P.D., Fitzgerald, S.M. and Merchant, W.R. 2010: Using scoping literature reviews as a means of understanding and interpreting existing literature. Work - A Journal of Prevention Assessment and Rehabilitation 35, 399-404.

Russell, G., Geneau, R., Liddy, C., Hogg, W., and Hogan, K. 2007: Mapping the future of primary healthcare in Canada: 
A report to the Canadian Health Services Research Foundation. Ottawa: Canadian Health Services Research Foundation.

Russell, G., Sutton, J., Reid, G.J., Beynon, C., Cohen, I. and Huffman, D. 2003: Universal influenza immunization. Were Ontario family physicians prepared? Canadian Family Physician 49, 1315-21.

San Martin-Rodriguez, L., Beaulieu, M.D., Amour, D. and Ferrada Videla, M. 2005: The determinants of successful collaboration: a review of theoretical and empirical studies. Journal of Interprofessional Care 19 (Suppl. 1), 132-47.

Sanders, M.R., Ralph, A., Sofronoff, K., Gardiner, P., Thompson, R., Dwyer, S. and Bidwell, K. 2008: Every family: a population approach to reducing behavioral and emotional problems in children making the transition to school. Journal of Primary Prevention 29, 197-222.

Scott, R.J. 1999: Toward self-empowered community teams within Inuvik Regional Health and Social Services Board. Dissertation/thesis. Canada: Royal Roads University.

Shandro, G. 2003: Primary care partnerships project: the Crowfoot Project. Health Innovation Fund Project no. 81. Final project team report. Retrieved 29 August 2008 from http://www.health.alberta.ca/key/phc_IE_081Primary PartnershipsProject.pdf

Shaw, S., Ashcroft, J. and Petchey, R. 2006: Barriers and opportunities for developing sustainable relationships for health improvement: the case of public health and primary care in the UK. Critical Public Health 16, 73-88.

Shirin, E., Scotten, E.S. and Absher, A.C. 2006: Creating community-based access to primary healthcare for the uninsured through strategic alliances and restructuring local health department programs. Journal of Public Health Management and Practice 12, 446-51.

Starfield, B. 1998: Primary care: balancing health needs, services and technology. New York: Oxford University Press.

Stevenson Rowan, M.S., Hogg, W. and Huston, P 2007: Integrating public health and primary care. Healthcare Policy/Politiques de Santq 3, 1-22.

Taylor, M., Stokes, W., Bajuscak, R., Serdula, M., Siegel, K., Griffin, B., Keiser, J., Agate, L., Kite-Powell, A., Roach, D., Humbert, N., Brusuelas, K. and Shekar, S. 2007: Mobilizing mobile medical units for hurricane relief: The United States Public Health Service and Broward County Health Department response to hurricane Wilma, Broward County, Florida. Journal of Public Health Management and Practice 13, 447-52.

Thackway, S.V., Delpech, V.C., Jorm, L.R., McAnulty, J.M. and Visotina, M. 2000: Monitoring acute diseases during the Sydney 2000 Olympic and Paralympic games. Medical Journal of Australia 173, 318-21.

The Change Foundation. 2009: Integrated health care in England: lessons for Ontario. Toronto: The Change Foundation.
The Leeds and Grenville and Lanark District Health Unit. 2000: Rideau district high school clinic evaluation. Retrieved 31 August 2008 from http://www.healthunit. org/reportpub/evaluations/rideau_clinic.pdf

The Network Towards Unity for Health. 2008: Integrating medicine and public health. Retrieved 31 August 2008 from http:/www.the-networktufh.org/publications_resources/ positioncontent.asp? $\mathrm{id}=8 \mathrm{andt}=$ Position + Papers

Thomas, C.P., Cashman, S. and Fulmer, H. 1995: The cluster committee: setting the stage for community-responsive care. American Journal of Preventive Medicine 11, 9-18.

Valaitis, R., Martin-Misener, R., Wong, S., MacDonald, M., Meagher-Stewart, D., Austin, P., Kaczorowski, J., and O-Mara, L. and the Strengthening Primary Health Care through Public Health and Primary Care Collaborations Team. 2011. Methods and technologies strategies used in conducting a scoping literature review of collaboration between primary care and public health. Primary Health Care Research and Development (in press).

Voelker, R. 1994: Population-based medicine merges clinical care, epidemiologic techniques. Journal of the American Medical Association 271, 1301-02.

Wedel, R., Kalischuk, R.G. and Patterson, E. 2007: Turning vision into reality: successful integration of primary healthcare in Taber, Canada. Healthcare Policy/Politiques de Santq 3, 80-95.

Weiss, E.S., Anderson, R.M. and Lasker, R.D. 2002: Making the most of collaboration: exploring the relationship between partnership synergy and partnership functioning. Health Education and Behavior 29, 683-98.

Welton, W.E., Kantner, T.A. and Katz, S.M. 1997: Developing tomorrow's integrated community health systems: a leadership challenge for public health and primary care. Milbank Quarterly 75, 261-88.

Wiles, R. and Robison, J. 1994: Teamwork in primary care: the views and experiences of nurses, midwives and health visitors. Journal of Advanced Nursing 20, 324-30.

Williams, J.F., Riegelman, R.K. and Grossman, J.H. 1999: Academic health centers can bridge the gulf between medicine and public health. Academic Medicine 74, 484-87.

Wilson, A.H., Wold, J.L., Spencer, L. and Pittman, K. 2000: Primary health care for Hispanic children of migrant farm workers. Journal of Pediatric Health Care 14, 209-15.

Wood, N., Farrow, S. and Elliott, B. 1994: A review of primary health-care organization. Journal of Clinical Nursing 3, 243-50.

World Health Organization (WHO). 1978: Declaration of Alma Ata. Geneva: WHO.

World Health Organization (WHO). 2008: Primary health care - now more than ever. Geneva: WHO.

Xyrichis, A. and Lowton, K. 2008: What fosters or prevents interprofessional teamworking in primary and community care? A literature review. International Journal of Nursing Studies 45, 140-53. 